\title{
A study on the cooperation of vocational education and applied degree education courses
}

\author{
Cao Bingzhi \\ Faculty of Education, Beijing Normal University Beijing 100875
}

\begin{abstract}
By the analysis of the existing type structure of higher education in China and the contradictions and problems of the current structure, the exposition of the relationship between academic and applied education, vocational education and higher education, the analysis of the essential characteristics of higher vocational education courses, the paper proposed the design ideas and vision of applied degree curriculum, and proposed the effective cooperation mode between vocational education and applied degree education courses. Proposed cooperation mode has the advantages that analysis of issues of strong principle, the idea put forward practical and feasible, and can play a guiding role on deepening the reform of higher education and fulfilling vocational education and applied degree education effective cooperation. Through interaction among the whole society to enhance development of higher vocational education in China, together to create a good situation those students learning something, teachers teach something and the society uses something. Thus we can fulfill the scientific development of higher education, and long-term development.
\end{abstract}

Keywords-vocational education; applied degree education; courses cooperation

\section{INTRODUCTION}

It can be used two types of 3 to represent higher education framework, the details are: two types refers to ordinary continue higher education and higher education, three refers to a college education, undergraduate education and postgraduate education. The design of such a structure is also difficult to see its unreasonable positioning; however in higher vocational education it will be able to see the true meaning of positioning: higher vocational education is only at specialist level, so greatly limits higher vocational education development. Considering type structure of higher education in China from the elite education era to era of popularization of higher education, although the architecture of education has changed, the ideas and models of education remains rigid and do not keep up with the time development needs, not close to the personnel training needs of socialistic market economy.

Currently, higher vocational education cooperation with undergraduate and postgraduate education can't be applied and be limited to the college level. The society offered only a handful of undergraduate higher vocational college. This has led the development of vocational education is limited, social status also difficult to improve. Only by establishing the Higher Vocational Undergraduate Vocational - Master - PhD consistent system of modern vocational education system, high level vocational education can development to complement the regular higher education and to develop specialized senior technical talents as the goal, in order to meet the demand of the people to receive vocational education and to meet the need of the socialistic market economy for high-quality, skilled personnel ${ }^{[1-3]}$.

Professional degree, also known as a vocational degree is a degree type relative to academic degrees. Professional degree education's is to cultivate the special practical high-level personnel for society which required for a specific job or post, it is a different type academic type from the degree education but same genus level, and with the same general type of vocational education and but different levels. It belongs to graduate-level vocational education, and is a high level of education vocational education. ${ }^{[4-6]}$.

\section{THE DEVELOPMENT OF VOCATIONAL EDUCATION ABOUT THE TYPE OF EDUCATION STRUCTURE}

College training personnel as the main direction of theoretical research leads to the situation that students trained professional theory, but practical ability is weak. In addition to research institutions which need research talent, general employers should focus on the practical ability of graduates. For many employers the idea of employing a certain extent has further exacerbated the conflict. They often consider the academic qualifications as a prerequisite in the recruitment of college students, thus caused the illusion that high academic credentials will be able to have a good job, those who have qualifications but weak capacity can't adapt to work after being employed. This can result in frequent job-hopping; graduates' future can be affected and the employer also suffered large losses. Similar to the status quo of this vocational graduate employment uncoordinated can be described as educational or professional curriculum. Therefore, firstly we do systematic analysis and comprehensive consideration of type of education and structural development of vocational education constitutes. To come up with a well-established and successful school vocational education courses optimization cooperation program. The curriculum is the three-stage model which of its type structure is as shown in (Figure 1). 


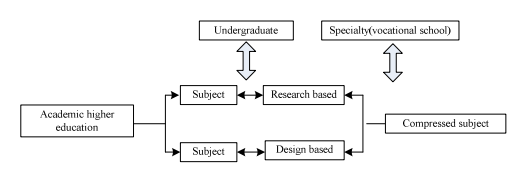

Figure 1 type structure of higher education in elite education era

The curriculum model of Research discipline curriculum is the pure discipline type. Courses which nurturing design talent is still pure subject-courses, there is no essential difference between that and which training research personnel. Maybe it has reduced the corresponding theoretical subjects, and increase application. Because design disciplines students after graduation can directly take task, people call it the "applied education” which cultures the "applied” talents. However its essential character has not changed. Tracing academic, we can see same educational methods and curriculum models. Sadly, specialist education although seemingly has the applied nature, but its curriculum model set is simply compression from the undergraduate education courses. The structure type of the higher education should be adjusted structure which is shown in Figure 2:

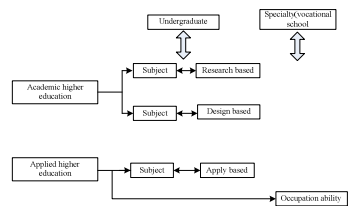

Figure 2 type structure of popularized higher education

Based on the above type structure, it can be seen that the main task of the Chinese higher education should be: to take drastic measures to deepen the reform of higher education, to make the quality of education continue to be at a higher level, at full speed to promote the development of application-oriented undergraduate education. At the same time continuing vocational carried out in-depth education reform, and call must be carried out, the line must be fruit, and promote the continuous development of vocational education. So that the majority of vocational high school students can become useful for the community to use, make the best use of the talents and really be used in the vocational. High school students can use career knowledge learned in the actual job, contribute youthful wisdom for the socialistic modernization, instead of being underachievement, timid, and cannot seek employment.

\section{THE ESSENTIAL CHARACTERISTICS OF THE VOCATIONAL EDUCATION COURSES}

The essential characteristics of higher vocational education courses and applied degree programs are similar, but there are also different, this is because the latter are still more for subject knowledge, emphasis on professional competence and vocational courses. Exploring the essential characteristics of the vocational education curriculum is good for optimizing cooperation and professional degree to achieve the optimal configuration of the curriculum.

\section{BEGINNING AND END PROBLEM OF THE VOCATIONAL EDUCATION COURSES}

To achieve the optimization settings and cooperation of higher education course, the first faced problem is the set start and end points of vocational education courses, the original intention and purpose of higher education programs must be clear. We should individualized for tertiary teaching while education, not for education settings, and the merger has nothing to do with the professional courses in order to save credits and teaching resources, which is both the most fundamental teaching resources wasted and be irresponsible for vocational education and students. Therefore, it must be in line with the purpose and intention to apply their knowledge to find the starting point of the vocational education curriculum. Eventually carried out, that is to apply what they have learned, learning that truly let the students have learned to use, learn a director which the talents needed by the society. In short, a career-oriented professional setting and curriculum design as a starting point in order to achieve the students future posts adaptability as the purpose, which is that vocational education courses is different from regular higher education as an important aspect.

\subsection{The professional curriculum design problems}

Reforms brought about by the shift in attitudes are a series of things. Employment-oriented vocational ability accounts for a dominant position, and thus there have been a large change in the appropriate curriculum design. This transformation can be summarized as two curriculum systems: vertical tandem courses and parallel ladder curriculum and the vertical series courses led tied for the ladder curriculum for the secondary, separately:

\section{CURRICULUM DESIGN IDEAS AND VISION OF APPLIED DEGREE}

Applied higher education is a new type of education which following undergraduate higher education diversification. It has begun in the education to explore, research and practice. Some experts and scholars have understanding deviation on the basic characteristics of "application", they think that the academic undergraduate education can be visualized as "applied education". The reason is that the academic undergraduate education's purpose is also the social applications. Between application and academic the essential difference is that: the Applied Higher trained people who are applied people in production and living services, if they stop working will result in the production and living services directly interrupt. In this sense, the Academic Higher Education training of personnel engaged in the production life is long-term; they stop working without causing direct interrupt of production and living services. 


\subsection{Applied undergraduate education training objectives}

Today the country's higher education personnel train can be two broad categories. One is for academic talent and the other for applied talents training. Academic-type learning talent stands on a theoretical level to explore the theoretical depth and to make quiet inaction contribution for the natural and scientific progress of the human society. They are ladder of human academic and the driving force behind the development of science. Applied personnel stand in the front-line of scientific research development, perhaps occupying the front line of technology workers, perhaps being program designers. Their presence leads to the achievements of the birth of one and another application project. Considering the characteristics of vocational students, based on high vocational students as the main goal of Applied Talents it can be largely divided into four categories, namely technical talents, composite application talent, service application talents and career applied talents. Perhaps it's a combination of two types, perhaps both academic applications talents. The training objectives of applied are shown in Figure 3.

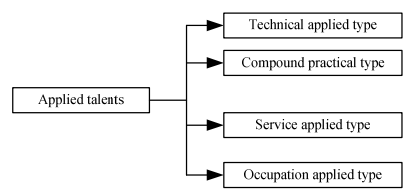

Figure 3 applied higher education training objectives

\section{THE APPLICATION-DEGREE SYSTEM}

\subsection{Curriculum framework}

The towering building comes from the ground, also higher and state-of-the-art educational philosophy needs discipline-based support, and basic theoretical knowledge to build up the curriculum system. By emphasizing the application of academic higher education, it is proposed in recent years that undergraduate education needs to reflect the application. It is necessary to increase the proportion of practice teaching and advocate the implementation of the synchronous development of teaching the theory and practice of teaching. They are separate and cooperate with each other, but overall practice teaching still just dominates theoretical teaching.

\subsection{The disciplines basic platform and its course system}

The curriculum system set with its clear purpose: to lay a solid basis for ability, to improve the ability of students to use the theory to guide practice work. It has three distinct characteristics: First, Curriculum Studies Foundation some extent reduces the difficulty and depth, enhancing the application. Second, studies foundation should strengthen the teaching target of applied higher education, based on the division of the professional belongs disciplines. Third, applied education curriculum is in the practice of teaching, but also should be in accordance with the principle of first theory, after practice, thus focus on training the students' sense of teamwork in practice to.

\subsection{Curriculum system of application capabilities}

The key of applied talents is to train competence for future work. Application capacity curriculum system has the following characteristics: First, the application of the ability be classified in accordance with the general purpose and specialized. Second, the training process is divided into experiential knowledge accumulation and procedural deposition of procedural knowledge and application ability process requires the accumulation of empirical knowledge and process knowledge. Third, curriculum system emphasizes combination of application and capabilities on theory and practice, but rather more prominent practice.

\section{EFFECTIVE COOPERATION OF VOCATIONAL EDUCATION COURSES AND APPLIED DEGREE PROGRAMS}

Employment-oriented curriculum design system of higher vocational education will not infringe on the power of the students' wants to continue to learn, but they need to handle the relationship of upgrade and employment. By considering at all levels of higher education the relationship between the various systems and their respective training objectives and curriculum design concept, there comes a certain understanding of vocational education and applied degree education courses cooperation problem: Higher Vocational Education and Higher Education applied are at different levels, but all have the common feature of applied, so the cooperation of the course is relatively easy. Applications and academic differences between vocational education and academic higher education make their cooperation more difficult: If we use the way to mutual recognition of credits then will cause academic structure extended. Academic-type education research programs almost have no credits can be recognized, and need to re-learn.

\section{CONCLUSION}

With the deepening of the reform of higher education, vocational education will also usher in a new development. It is not impossible to achieve effective cooperation between vocational education and applied degree education courses. The key is to maintain the fundamental nature of the vocational education and applied degree education which lies in the philosophy of course design. How to deepen the reform of higher education to establish a high quality and efficient training model, the exploring still has a long way to go. At the same time it requires the cooperation of departments at all levels. Through the advice and suggestions of teachers and students, the substance of the expert advice and research, employer counterparts' guidance, up and down the interaction, we can jointly be committed to the development of higher vocational education in China. Thus can we work together to create a good situation that student learning something, teach teachers something and 
the community use something. Thus we can see the scientific development and long-term development of vocational education and even the cause of higher education.

\section{REFERENCES:}

[1] Chen Chaowen. Discussions on the Reform of Tanching Practice for Computer Science Majors[J]. Journal of Nanning Teachers College, 2005, 22(3):75-77.

[2] DENG Jing-sheng. The new view about reform of the method of pre-service teacher education practice under the background of new curriculum[J]. CAREER HORIZON, 2012, 8(9): 81-83.

[3] Hulman LS.. Knowledge and Teaching: Foundations of the New Reform[J]. Harvard Educational Review, 1987, 57 (1): 135-143.

[4] LIU Xu-dong. On Educational Practice Ability of Normal Students and the Reform of Education and Internship Program[J]. Contemporary Education and Culture, 2011, 3(2): 74-79.

[5] Kato, Takao. The End of Lifetime Employment in Japan: Evidence from National Surveys and Field Research [J]. Journal of the Japanese and International Economies, 2001, 4: 489-514.

[6] Tanova, C., Holtom, B.Using. Job Embeddedness Factors to Ex-plain Voluntary Turnover in 4 European Countries[J]. International Journal of Human Resource Management, 2008, 9: 1553-1568. 